\title{
Trace Analysis of Fifteen Androgens in Environmental Waters by LC-ESI-MS-MS Combined with Solid-Phase Disk Extraction Cleanup
}

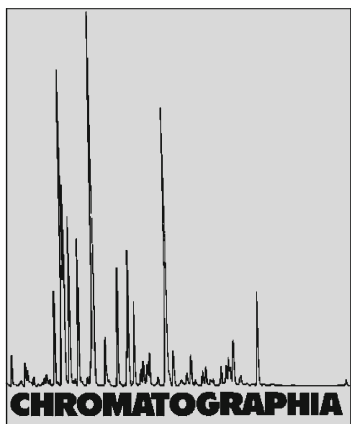

\author{
Li Sun ${ }^{1,2}$, Yan Liư ${ }^{3}$, Xiaogan $\mathrm{Chu}^{2}$, Jin-Ming Lin ${ }^{3, \mathbb{}}$ \\ 1 State Key Laboratory of Environmental Chemistry and Ecotoxicology, Research Center for Eco-Environmental Sciences, \\ Chinese Academy of Sciences, P.O. Box 2871, Beijing 100085, China \\ 2 Institute of Food Safety, Chinese Academy of Inspection and Quarantine, Beijing 100123, China \\ ${ }^{3}$ Analysis Center and Department of Chemistry, Tsinghua University, Beijing 100084, China; E-Mail: jmlin@mail.tsinghua.edu.cn
}

Received: 9 December 2009 / Revised: 13 January 2010/ Accepted: 25 February 2010

Online publication: 23 March 2010

\begin{abstract}
A rapid and sensitive liquid chromatography-electrospray tandem mass spectrometry method, combined with solid-phase disk extraction cleanup, was developed and applied to the analysis of fifteen androgens in waste water. Compounds included androstenedione, androstanolone, boldenone, clostebol, danazol, 6-dehydronandrolone acetate, fluoxymesterone, methyltestosterone, nandrolone, nandrolone propionate, testosterone, testosterone acetate, testosterone propionate, trenbolone and trenbolone acetate, respectively. The overall method recoveries ranged from 78.0 to $107.7 \%$ and the limits of detection for the fifteen analytes determined in influent samples were between 0.5 and $4 \mathrm{ng} \mathrm{L}^{-1}$. The analysis of residual androgens was carried out in waste water obtained from the Beijing area and five analytes (androstenedione, fluoxymesterone, methyltestosterone, testosterone and nandrolone) could be detected in levels ranging from $1.6-3.5,7.6-66.7,4.1-7.0,1.2-4.3$ and $1.7 \mathrm{ng} \mathrm{L}^{-1}$, respectively.
\end{abstract}

\section{Keywords}

Column liquid chromatography

ESI-MS-MS

Solid-phase disk extraction

Environmental water

Androgens

\section{Introduction}

Androgens have been used as growth promoters in human and veterinary therapy and are found to be discharged into the aqueous environment via sewage treatment plants (STPs) [1]. Since androgens are responsible for developing and maintaining male sex characteristics in animals their androgenic character can affect the harmony of the biological environment [2]. Therefore, there is a need to develop a sensitive and reliable method for their detection in water matrices for assessing environmental risks.

Androgen is a steroid representative and a number of methods have been developed for detection of steroids derivatives. Immunoassay methods are the most sensitive analytical procedures available for the determination of steroidal hormones present in biological samples $[3,4]$ but are prone to cross reactivity with other endogenous hormones and metabolites. Mass spectrometry based methods also provide accurate and sensitive information and have been used to analyze two androgens in waste water effluents [5] or surface water samples [6] using gas chromatography-mass or tandem mass spectrometry [GC-MS(-MS)] after their derivatization. However, sample derivatization for the wide range of androgens proved complicated and not all androgens, such as stanozolol, could not be derivatized [7]. Alternative methods include the implementation of highperformance liquid chromatography MS (LC-MS) methodology where derivatization is often not needed. Recent examples reported in the literature include the analysis of androgens in waste water and surface water samples [8,9]. Although 


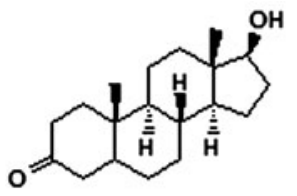

Androstan olone

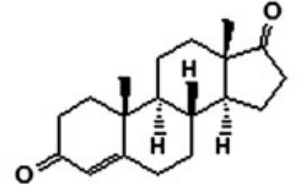

Androstenedione

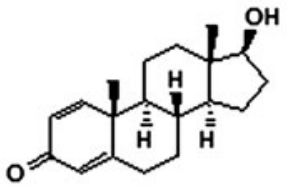

Boldenone<smiles>C[C@]12CCC(=O)C(Cl)=C1CC[C@@H]1[C@@H]3CC[C@H](O)[C@@H]3CC[C@@H]12</smiles>

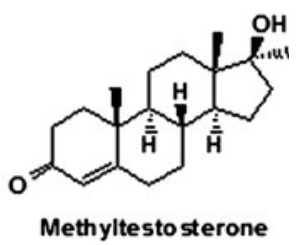

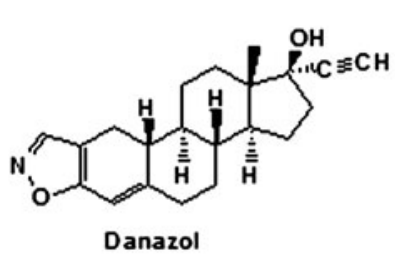<smiles>CC(O)O[C@H]1CC[C@H]2[C@@H]3C=C4C=C([O-])CC[C@]4(C)[C@H]3CC[C@]12C</smiles>

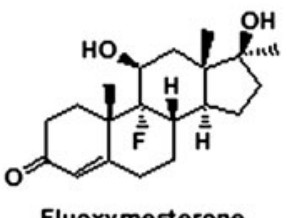

Fluoxymesterone

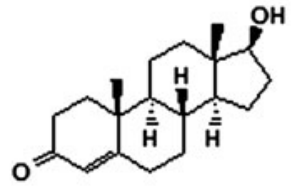

Testosterone<smiles>CC(=O)O[C@H]1CC[C@@H]2[C@@H]1CC[C@H]1[C@H]2CCC2C=C([O])CC[C@@]21C</smiles>

Testosterone acetate

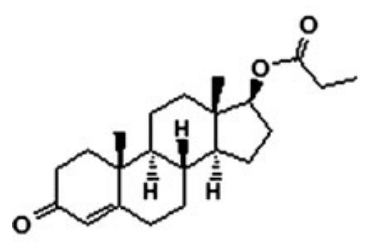

Testosterone propionate

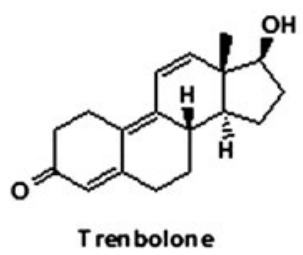

Trenbolone<smiles>CC(=O)O[C@H]1CCC2C3CCC4=CC(=O)CCC4=C3C=C[C@@]21C</smiles>

Tren bolone acetate

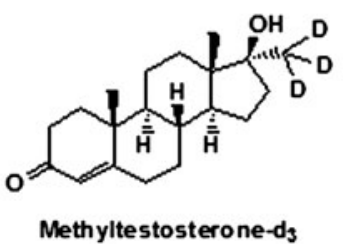

Fig. 1. Molecular structures of the investigated androgens

LC-MS(-MS) has been viewed as a potential method for analyzing a broad range of these compounds, matrix interference has been proven to cause potential problems.

In order to detect steroids in water at ng $\mathrm{L}^{-1}$ levels sample preparation procedures normally include extraction and enrichment steps. Liquid-liquid extraction (LLE) and solid-phase extraction (SPE) [10-12] are most commonly used extraction methods used for the determination of steroids. However, LLE requires the use of large volumes of organic solvents and additional clean-up steps and SPE methods can be tedious and time consuming. To overcome these problems, in-tube solid-phase microextraction [13], on-line SPE [14] and stir bar sorptive extraction $[15,16]$ have been developed successfully for the determination of these substances.

The present study aimed to develop a sensitive and specific method for the simultaneous analysis of fifteen androgens in waste water using $\mathrm{C} 18$ solid-phase disk extraction (SPDE) and LC-MS-MS analysis. This is the first time to employ C18 SPDE for the extraction and enrichment of androgens which helped to reduce sample preparation time. The target analytes (Fig. 1) included natural and synthetic androgens which have already been detected [5-9] or could be potentially present in the environment. The developed method has been applied to the analysis of these compounds in waste water obtained from the Beijing area.

\section{Experimental}

\section{Chemicals and Reagents}

Androstenedione (ASD), androstanolone (AST), boldenone (B), clostebol (C), danazol (D), 6-dehydronandrolone ace- tate (DHAA), fluoxymesterone (FT), methyltestosterone (MT), nandrolone (N), nandrolone propionate (NP), testosterone (T), testosterone acetate (TA), testosterone propionate (TP), trenbolone (TR), trenbolone acetate (TRA), $\left[{ }^{2} \mathrm{H}_{3}\right] \mathrm{MT}$ were obtained from Dr. Ehrenstorfer (Augsburg, Germany). Acetonitrile and methanol (HPLC grade) were purchased from Burdick and Jackson (Muskegon, MI, USA). Double distilled formic acid was from GFS Chemicals (Columbus, USA). Deionized water was obtained from a Milli-Q Plus 185TM coupled to an Elix 5TM system (Millipore, Schwalbach, Germany). The ENVI-18 (C18) and ENVI-8 (C8) SPE disk (47 mm diameter, $0.6 \mathrm{~mm}$ thickness) were supplied by Supelco (Bellefonte, PA, USA). Stock standard solutions of individual androgens $\left(1.0 \mathrm{mg} \mathrm{L}^{-1}\right)$ and internal standard $\left(1.0 \mathrm{mg} \mathrm{L}^{-1}\right)$ were used to prepare the working and calibration standard mixtures in methanol at the 
desired concentration, and were stored at $-20{ }^{\circ} \mathrm{C}$.

\section{Sample Preparation}

Water samples were collected in amber glass bottles and were taken from the influent of a waste water treatment plant and other samples were taken from the effluent of a fish farm located in the Beijing district. Samples were filtered through $0.2 \mu \mathrm{m}$ nylon membranes with a diameter of $47 \mathrm{~mm}$, stored in the dark at $4{ }^{\circ} \mathrm{C}$ and analyzed within $24 \mathrm{~h}$.

ENVI-18 SPE disks were used for purification of samples. Initially, the disk was washed with $10 \mathrm{~mL}$ methanol followed by $10 \mathrm{~mL}$ of deionized water. Afterwards, $200 \mathrm{~mL}$ water samples spiked with internal standard $\left(100 \mu \mathrm{g} \mathrm{L}^{-1}, 100 \mu \mathrm{L}\right)$ were drawn into the disk, dried under vacuum and eluted with $20 \mathrm{~mL}$ acetonitrile. The obtained extract was evaporated to dryness using a rotary evaporator, reconstituted in methanol to a final volume of $0.2 \mathrm{~mL}$ and filtered through a $0.2 \mu \mathrm{m}$ syringe filter (13 mm diameter, Pall, NY, USA) for further LC-MS-MS analysis. The same procedure was employed when using a C8 disk.

\section{LC-MS-MS Analysis}

Chromatographic separation was carried out using an Agilent LC 1200 system coupled to an Applied Biosystems API 5000 triple quadrupole mass spectrometer. Separation was achieved on a CAPCELL PAK C18 MG column $(75 \times$ $2.0 \mathrm{~mm}, 3 \mu \mathrm{m}$ ) (Shiseido, Tokyo, Japan) and injection volume was set at $5 \mu \mathrm{L}$. The mobile phase flow rate was

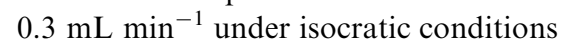
and the column temperature was set at $30{ }^{\circ} \mathrm{C}$. The mobile phases consisted of methanol (A) and deionized water containing $0.1 \%$ formic acid (B). Gradient conditions were: $40 \%$ A held for $2 \mathrm{~min}$ followed by a linear increase to $60 \% \mathrm{~A}$ within $5 \mathrm{~min}$, then changed to $95 \% \mathrm{~A}$ within $8 \mathrm{~min}$, and held at 95\% A for $5 \mathrm{~min}$. Before the next injection the mobile phase returned to initial condi-

Table 1. Retention time, selected reaction monitoring conditions (ESI) used for LC-MS-MS detection

\begin{tabular}{|c|c|c|c|c|c|}
\hline Analyte & $\begin{array}{l}\text { Retention } \\
\text { time (min) }\end{array}$ & $\begin{array}{l}\text { Precursor } \\
\text { ion }(m / z)\end{array}$ & $\begin{array}{l}\text { Declustering } \\
\text { potential (V) }\end{array}$ & $\begin{array}{l}\text { Product } \\
\text { ions }(m / z)\end{array}$ & $\begin{array}{l}\text { Collision } \\
\text { energy (V) }\end{array}$ \\
\hline \multirow[t]{2}{*}{ ASD } & \multirow[t]{2}{*}{7.39} & \multirow[t]{2}{*}{287} & \multirow[t]{2}{*}{115} & 97 & 42 \\
\hline & & & & 109 & 36 \\
\hline \multirow[t]{2}{*}{ AST } & \multirow[t]{2}{*}{11.5} & \multirow{2}{*}{291} & \multirow{2}{*}{150} & 255 & 21 \\
\hline & & & & 119 & 42 \\
\hline \multirow[t]{2}{*}{ B } & \multirow[t]{2}{*}{6.94} & \multirow[t]{2}{*}{287} & \multirow[t]{2}{*}{110} & 121 & 40 \\
\hline & & & & 135 & 17 \\
\hline \multirow[t]{2}{*}{$\mathrm{C}$} & \multirow[t]{2}{*}{11.38} & \multirow[t]{2}{*}{323} & \multirow[t]{2}{*}{140} & 143 & 42 \\
\hline & & & & 131 & 42 \\
\hline \multirow[t]{2}{*}{ D } & \multirow[t]{2}{*}{12.98} & \multirow[t]{2}{*}{338} & \multirow[t]{2}{*}{152} & 148 & 35 \\
\hline & & & & 120 & 49 \\
\hline \multirow[t]{2}{*}{ DHAA } & \multirow[t]{2}{*}{12.54} & \multirow[t]{2}{*}{315} & \multirow[t]{2}{*}{73} & 133 & 36 \\
\hline & & & & 159 & 32 \\
\hline \multirow[t]{2}{*}{ FT } & \multirow[t]{2}{*}{7.26} & \multirow[t]{2}{*}{337} & \multirow[t]{2}{*}{112} & 241 & 35 \\
\hline & & & & 131 & 48 \\
\hline \multirow[t]{2}{*}{ MT } & \multirow[t]{2}{*}{10.43} & 303 & 130 & 97 & 40 \\
\hline & & & & 109 & 40 \\
\hline $\mathrm{N}$ & 7.58 & 275 & 110 & 109 & 40 \\
\hline & & & & 91 & 65 \\
\hline NP & 14.17 & 331 & 130 & 239 & 24 \\
\hline & & & & 275 & 28 \\
\hline $\mathrm{T}$ & 8.97 & 289 & 130 & 97 & 38 \\
\hline & & & & 109 & 40 \\
\hline TA & 13.62 & 331 & 103 & 109 & 36 \\
\hline & & & & 289 & 25 \\
\hline TP & 14.67 & 345 & 100 & 97 & 39 \\
\hline & & & & 109 & 32 \\
\hline TR & 6.66 & 271 & 150 & 199 & 34 \\
\hline & & & & 107 & 45 \\
\hline TRA & 12.11 & 313 & 143 & 253 & 35 \\
\hline & & & & 211 & 40 \\
\hline IS & 10.43 & 306 & 130 & 97 & 40 \\
\hline & & & & 109 & 40 \\
\hline
\end{tabular}

For abbreviations refer to "Experimental" section

tions for equilibration. Ionization and fragmentation settings were optimized by direct injection of standard solutions. MS-MS was performed in the selected reaction monitoring mode (SRM) using ESI in the positive ion mode. For each compound, two characteristic fragmentations of the protonated molecule were monitored (Table 1) where the first transition was used for quantification and the second was used as a qualifier transition.

Collision energy and declustering potential were optimized for each analytes (Table 1). Other parameters were optimized as follows: ionspray voltage $5500 \mathrm{~V}$, desolvation temperature $550{ }^{\circ} \mathrm{C}$ and dwell time $20 \mathrm{~ms}$. Nitrogen was used as collision gas (5 psi), curtain gas (20 psi), ion source gas 1 (55 psi) and ion source gas 2 (55 psi). Data were acquired using Analyst 1.5 software. Representa- tive SRM chromatograms are shown in Fig. 2.

\section{Data Analysis}

Identification of analytes was performed by comparing the retention times and MS signals obtained from samples with those obtained using standard solutions. Furthermore, for LC-MS-MS analyses, the ratio of the two precursor-product ion transitions was compared with that observed with authentic standard (using a tolerance of $\pm 30 \%$ ). Concentrations were determined using linear regression analysis of the peak area. A five point calibration curve, using the internal standard methodology, covered the range between 0.5 and $100 \mu \mathrm{g} \mathrm{L}^{-1}$. The concentration of the internal standard in all calibration mixtures was $50 \mu \mathrm{g} \mathrm{L}^{-1}$. 


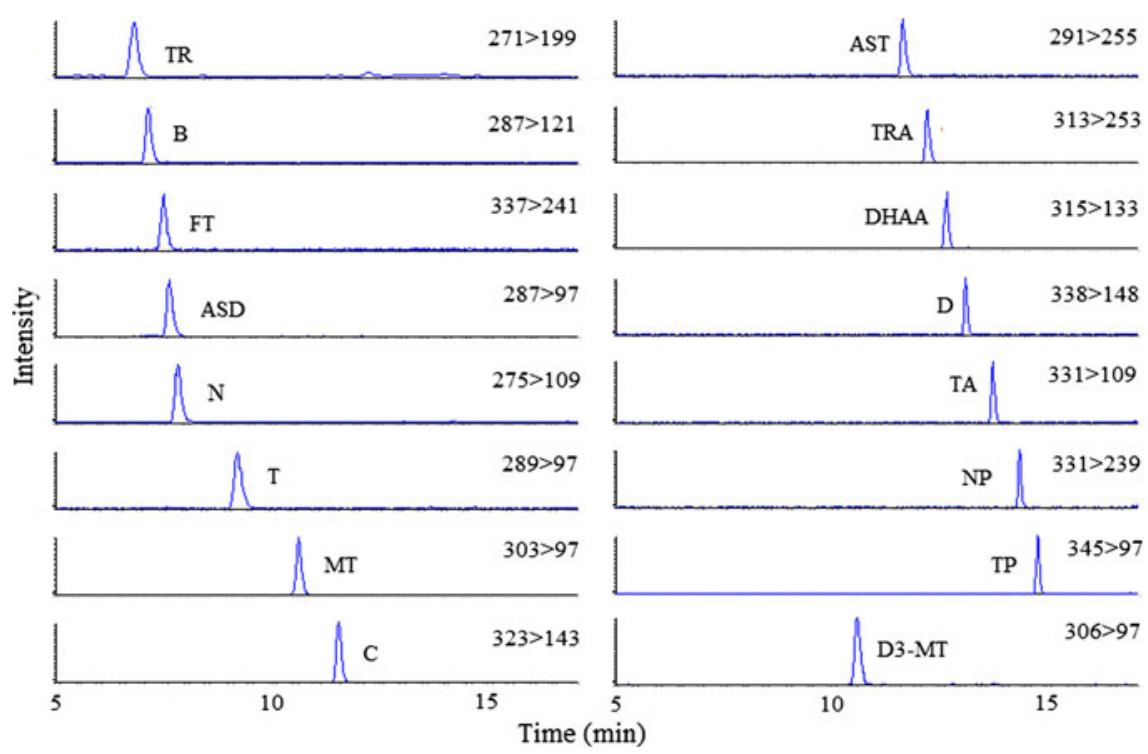

Fig. 2. Representative SRM chromatograms corresponding to androgen standard solutions at $10 \mathrm{ng} \mathrm{mL}^{-1}$

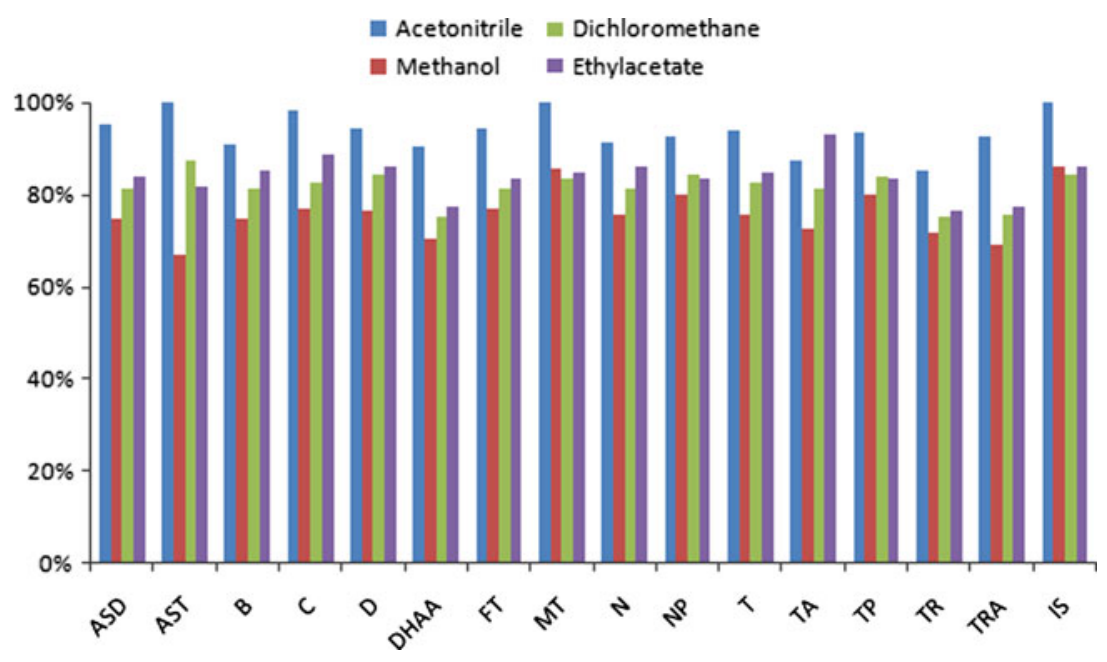

Fig. 3. Effects of the different elution solvents. Each deionized water sample was spiked with androgens at $50 \mathrm{ng} \mathrm{mL}^{-1}$ using an extraction speed of $150 \mathrm{~mL} \mathrm{~min}{ }^{-1}$

\section{Results and Discussion \\ Optimization of SPDE Conditions}

SPE is a commonly used extraction method for the isolation of hormones from water and is known to show excellent extraction efficiency. Since the SPE cartridges need much more time for the treatment of large volumes of water samples it was deemed necessary to explore the use of SPE disks in order to reduce sample preparation time $[17,18]$. A comparison between C18 and C8 SPE disks revealed that former was found to give excellent recoveries whereas the latter was observed to give unsatisfactory analyte retention. In order to optimize extraction speed, extraction recovery experiments were performed with spiked standard solutions in ultrapure water at $50 \mathrm{ng} \mathrm{L}^{-1}$. The extraction speed involved flow rates at 50,100 and $150 \mathrm{~mL} \mathrm{~min}^{-1}$ and it was determined that the extraction efficiency changed little at the different flow rates. Consequently, the SPDE extraction was

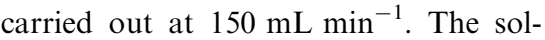
vent of choice used for elution of standard solutions was determined from the evaluation of acetonitrile, ethyl acetate, methanol and dichloromethane, respectively. A comparison of results showed that acetonitrile was the best elution solvent for most analytes (Fig. 3). When investigating elution volumes it was found that $20 \mathrm{~mL}$ acetonitrile were sufficient for the elution of analytes.

\section{Optimization of LC-M-MS and Method Performance}

In this study tandem mass spectrometry (MS-MS) was used to identify and quantify the analytes. Fifteen selected androgenic compounds were exposed to both positive and negative electrospray ionization and it was observed that androgens were efficiently ionized in positive ion mode which was consistent with previous reports [8, 9]. Therefore, all subsequent analyses were carried out in the positive ion mode using the LCMS-MS method.

The investigation of analytical method parameters included reproducibility and limit of detection (LOD). The ranges of linearity for the fifteen androgens were calculated and calibrated based on internal standardization using five concentration levels. Table 2 summarizes the calibration results, detection limits, and linear ranges and the correlation coefficients $\left(r^{2}\right)$ exceeded 0.996. The instrumental detection limits (IDLs) and the limits of detection (LODs) were defined as the concentrations that yielded $\mathrm{S} / \mathrm{N}$ ratios equal to 3 . The latter were determined through SPDE of spiked waste water samples. The IDLs and LODs ranged from 0.5 to $10 \mathrm{ng} \mathrm{L}^{-1}$ and 0.5 to $4 \mathrm{ng} \mathrm{L}^{-1}$, respectively.

The accuracy of this method was determined by calculating recovery and precision was determined by calculating relative standard deviation (RSD). Intraassay recoveries of the method were determined by analyzing tap water and waste water spiked with androgens at 10 and $50 \mathrm{ng} \mathrm{L}^{-1}$, respectively. Table 3 summarized the recoveries obtained from determinations of the fifteen analytes in various water matrices. The recoveries ranged between 78.0-96.4\% for tap water and $89.9-107.7 \%$ for waste 
Table 2. Calibration results, values of IDLs and LODs, and linear ranges

\begin{tabular}{|c|c|c|c|c|c|}
\hline Analyst & Linear regression & $r^{2}$ & Linear range $\left(\mu \mathrm{g} \mathrm{L}^{-1}\right)$ & IDLs (ng) & $\operatorname{LODs}\left(\mu \mathrm{g} \mathrm{L}^{-1}\right)$ \\
\hline ASD & $y=0.00515 x+0.0233$ & 0.999 & $0.5-100$ & 2.5 & 1.5 \\
\hline AST & $y=0.0093 x+0.000969$ & 0.999 & $1-100$ & 5 & 4 \\
\hline B & $y=0.0382 x+0.0105$ & 0.997 & $0.5-100$ & 2.5 & 4 \\
\hline $\mathrm{C}$ & $y=0.0259 x+0.00431$ & 0.999 & $0.3-100$ & 1.5 & 2 \\
\hline $\mathrm{D}$ & $y=0.00864 x+0.000685$ & 0.999 & $0.5-100$ & 2.5 & 2 \\
\hline DHAA & $y=0.00345 x+0.00867$ & 0.999 & $0.4-100$ & 2 & 2 \\
\hline FT & $y=0.00525 x-0.000367$ & 0.998 & $2-100$ & 10 & 4 \\
\hline MT & $y=0.0435 x+0.0167$ & 0.999 & $0.2-100$ & 1 & 0.6 \\
\hline $\mathrm{N}$ & $y=0.0241 x-0.00673$ & 0.996 & $1-100$ & 5 & 1.6 \\
\hline NP & $y=0.0104 x+0.00237$ & 0.999 & $1-100$ & 5 & 2 \\
\hline $\mathrm{T}$ & $y=0.0402 x-0.00179$ & 0.998 & $0.4-100$ & 2 & 0.8 \\
\hline TA & $y=0.0423 x+0.0064$ & 0.998 & $0.4-100$ & 2 & 4 \\
\hline $\mathrm{TP}$ & $y=0.0661 x+0.0142$ & 0.999 & $0.1-100$ & 0.5 & 0.5 \\
\hline TR & $y=0.0078 x-0.00229$ & 0.997 & $2-100$ & 10 & 4 \\
\hline TRA & $y=0.069 x+0.0128$ & 0.999 & $0.2-100$ & 1 & 1 \\
\hline
\end{tabular}

For abbreviations refer to "Experimental" section

Table 3. Precision and accuracy data $(n=5)$

\begin{tabular}{|c|c|c|c|c|c|c|c|c|}
\hline \multirow[t]{2}{*}{ Analyte } & \multicolumn{2}{|c|}{ Tapewater $+10 \mathrm{ppb}$} & \multicolumn{2}{|c|}{ Tapewater $+50 \mathrm{ppb}$} & \multicolumn{2}{|c|}{ Sample $1+10 \mathrm{ppb}$} & \multicolumn{2}{|c|}{ Sample $1+50 \mathrm{ppb}$} \\
\hline & $\begin{array}{l}\text { Recovery } \\
(\%)\end{array}$ & $\begin{array}{l}\text { RSD } \\
(\%)\end{array}$ & $\begin{array}{l}\text { Recovery } \\
(\%)\end{array}$ & $\begin{array}{l}\text { RSD } \\
(\%)\end{array}$ & $\begin{array}{l}\text { Recovery } \\
(\%)\end{array}$ & $\begin{array}{l}\text { RSD } \\
(\%)\end{array}$ & $\begin{array}{l}\text { Recovery } \\
(\%)\end{array}$ & $\begin{array}{l}\text { RSD } \\
(\%)\end{array}$ \\
\hline ASD & 95.6 & 0.8 & 95.1 & 1.8 & 91.1 & 5.6 & 89.8 & 7.4 \\
\hline AST & 82.0 & 7.4 & 92.9 & 4.3 & 96.4 & 11.9 & 93.9 & 9.7 \\
\hline B & 93.3 & 2.0 & 93.1 & 2.7 & 98.1 & 17.7 & 92.5 & 6.6 \\
\hline $\mathrm{C}$ & 94.5 & 3.6 & 89.1 & 3.1 & 91.2 & 2.6 & 96.4 & 5.3 \\
\hline D & 84.0 & 1.0 & 84.0 & 2.0 & 90.3 & 11.4 & 92.6 & 4.1 \\
\hline DHAA & 96.4 & 3.3 & 88.0 & 2.0 & 98.8 & 7.1 & 93.5 & 11.7 \\
\hline FT & 95.4 & 1.3 & 93.9 & 0.3 & 99.1 & 7.4 & 104.2 & 8.0 \\
\hline MT & 95.7 & 3.8 & 92.8 & 2.5 & 98.4 & 11.2 & 94.8 & 6.6 \\
\hline $\mathrm{N}$ & 92.1 & 2.5 & 97.7 & 2.5 & 102.9 & 2.2 & 99.8 & 7.3 \\
\hline NP & 85.2 & 2.9 & 89.9 & 4.2 & 89.9 & 5.3 & 96.7 & 5.1 \\
\hline $\mathrm{T}$ & 95.5 & 2.5 & 92.9 & 3.6 & 98.9 & 14.4 & 99.0 & 6.4 \\
\hline TA & 86.1 & 1.7 & 82.9 & 5.2 & 104.9 & 7.9 & 85.5 & 5.3 \\
\hline $\mathrm{TP}$ & 78.0 & 1.3 & 86.2 & 3.6 & 90.6 & 7.7 & 90.6 & 6.6 \\
\hline TR & 80.1 & 1.6 & 92.7 & 6.3 & 107.7 & 7.3 & 97.2 & 1.6 \\
\hline TRA & 83.7 & 2.0 & 87.1 & 2.3 & 101.2 & 10.1 & 92.6 & 13.3 \\
\hline
\end{tabular}

For abbreviations refer to "Experimental" section

water based on spiked samples at $10 \mathrm{ng}$ $\mathrm{L}^{-1}$. RSD values were found to range between $0.8-7.4 \%$ for tap water and $2.2-$ $14.7 \%$ for waste water, respectively. Recoveries and RSD values determined from spiked samples at $50 \mathrm{ng} \mathrm{\textrm {L } ^ { - 1 }}$ were found to yield similar results.

\section{Applications in Environmental Samples}

The proposed LC-MS-MS method was successfully applied to the analysis of androgens present in four waste water samples commonly found in the Beijing area and the mean concentrations of the detected analytes are reported in Table 4. Samples 1 and 2 were collected in waste water treatment plants and the remaining samples were collected from fish farms. Three natural androgens (ASD, T, N) and two synthetic androgens (FT, MT) were detected in the samples. $\mathrm{N}$ was only determined in sample 4 at a concentration of $1.7 \mathrm{ng} \mathrm{L}^{-1}$. MT and T were found in all waste water samples ranging from 4.1 to $7.0 \mathrm{ng} \mathrm{L}^{-1}$ and 1.2 to $4.3 \mathrm{ng} \mathrm{L}^{-1}$, respectively. ASD and FT were detected samples 2-4 that ranged between $1.6-3.5 \mathrm{ng} \mathrm{L}^{-1}$ and 7.6-66.7 $\mathrm{ng} \mathrm{L}^{-1}$, respectively.

Figure 4 shows a representative SRM LC-MS-MS chromatogram obtained after analysis of sample 4 . Detection of ASD and $\mathrm{T}$ reported in the present study was consistent with previously published data [9] but the presence of synthetic androgens (FT, MT) in waste water appear to be reported for the first time. Nowadays, FT and MT are used widely and substantially because they have good therapeutic effects in the treatment of male hypogonadism, delayed puberty in males, and in the treatment of breast neoplasms in women. FT is approximately five times more potent than MT and this might have been the reason of the high FT concentration found in sample 2 . 
Table 4. Concentrations of the androgens in waste water samples in Beijing $(n=3)$

\begin{tabular}{|c|c|c|c|c|}
\hline \multirow[t]{2}{*}{ Analyte } & \multicolumn{4}{|c|}{ Concentration $\left(\mathrm{ng} \mathrm{L}^{-1}\right)$} \\
\hline & Sample 1 & Sample 2 & Sample 3 & Sample 4 \\
\hline ASD & - & 3.5 & 1.6 & 2.1 \\
\hline AST & - & - & - & - \\
\hline B & - & - & - & - \\
\hline $\mathrm{C}$ & - & - & - & - \\
\hline D & - & - & - & - \\
\hline DHAA & - & - & - & - \\
\hline FT & - & 66.7 & 12.1 & 7.6 \\
\hline MT & 5.7 & 7.0 & 4.9 & 4.1 \\
\hline $\mathrm{N}$ & - & - & - & 1.7 \\
\hline NP & - & - & - & - \\
\hline $\mathrm{T}$ & 1.2 & 4.3 & 1.9 & 2.0 \\
\hline TA & - & - & - & - \\
\hline $\mathrm{TP}$ & - & - & - & - \\
\hline TR & - & - & - & - \\
\hline TRA & - & - & - & - \\
\hline
\end{tabular}

For abbreviations refer to "Experimental" section. "_": not detected
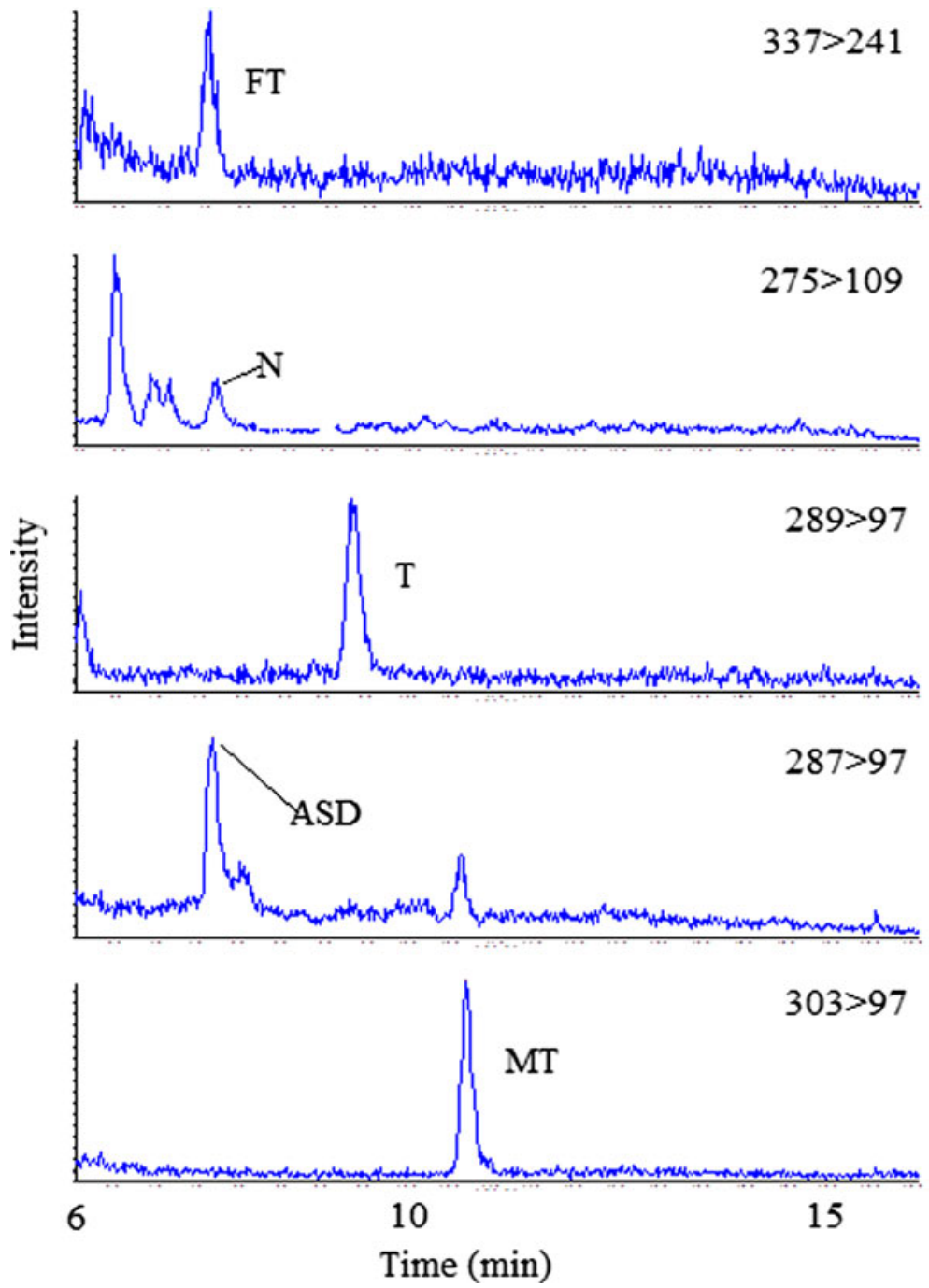

Fig. 4. SRM chromatograms of five androgens detected in sample 4

\section{Conclusion}

A method based on solid-phase disk extraction (SPDE) coupled with LC-MSMS analysis has been developed for the simultaneous determination of fifteen androgens in waste water. It was important to use SPDE in order to treat large volume water samples in short sample preparation time. This new method is an improvement in terms of simplicity and efficiency which should be applicable to androgen analysis as part of environmental studies. Based on the detection of natural and synthetic androgens present in these water samples it can be concluded that their monitoring within the Beijing district requires close attention.

\section{Acknowledgements}

This work was supported by the National Natural Science Foundation of China (No. 90813015).

\section{References}

1. Kumar V, Chakraborty A, Viswanath G, Roy P (2008) Toxicol Appl Pharmacol 226:60-73. doi:10.1016/j.taap.2007.08.023

2. Streck G (2009) Trends Anal Chem 28:635-652. doi:10.1016/j.trac.2009.03. 006

3. Scippo ML, Argiris C, Van de Weerdt C, Muller M, Willemsen P, Martial J, Maghuin-Rogister G (2004) Anal Bioanal Chem 378:664-669. doi:10.1007/s00216003-2251-0

4. Sohoni P, Sumpter JP (1998) J Endocrinol 158:327-339. doi:10.1677/joe.0.1580327

5. Kolodziej EP, Gray JL, Sedlak DL (2003) Environ Toxicol Chem 22:2622-2629. doi:10.1897/03-42

6. Kolodziej EP, Sedlak DL (2007) Environ Sci Technol 41:3514-3520. doi: 10.1021/es063050y

7. Joos PE, Ryckeghem MV (1999) Anal Chem 71:4701-4710

8. Yamamoto A, Kakutani N, Yamamoto K, Kamiura T, Miyakoda H (2006) Environ Sci Technol 40:4132-4137. doi: 10.1007/s00216-008-2451-8

9. Chang H, Wu SM, Hu JY, Asami M, Kunikane S (2008) J Chromatogr A 1195:44-51. doi:10.1016/j.chroma.2008. 04.055

10. López de Alda MJ, Barcelo D (2001) J Chromatogr A 938:145-153

11. Beck I, Bruhn R, Gandrass J, Ruck W (2005) J Chromatogr A 1090:98-106. doi: 10.1016/j.chroma.2005.07.013 
12. Matějicek D, Kubán V (2007) Anal Chim Acta 588:304-315

13. Mitani K, Fujioka M, Kataoka H (2005) J Chromatogr A 1081:218-224. doi: 10.1016/j.chroma.2005.05.058

14. Salvador A, Moretton C, Piram A, Faure R (2007) J Chromatogr A 1145:102-109. doi:10.1016/j.chroma.2007.01.055
15. Kawaguchi M, Ishii Y, Sakui N, Okanouchi N, Ito R, Inoue K, Saito K, Nakazawa H (2004) J Chromatogr A 1049:1-8. doi:10.1016/j.chroma.2004.08. 013

16. Almeida C, Nogueira JMF (2006) J Pharm Biomed Anal 41:1303-1311. doi:10.1016/j.jpba.2006.02.037
17. Bao ML, Pantani F, Barbieri K, Burrini D, Grifini O (1996) Chromatographia 42:227-233. doi:10.1007/BF02269658

18. Messer DC, Taylor LT (1995) J Chromatogr Sci 33:290-296 